\title{
Avaliação da Capacidade de Trabalho versus Envelhecimento dos Funcionários, num Município Português de média dimensão
}

rpso.pt/avaliacao-da-capacidade-de-trabalho-versus-envelhecimento-dos-funcionarios-num-municipio-portugues-de-media-

EVALUATION OF WORK CAPACITY VERSUS AGING OF EMPLOYEES, IN A PORTUGUESE MUNICIPALITY OF AVERAGE DIMENSION

TIPO DE ARTIGO: Observacional Analítico Transversal

AUTORES: Almeida A(1), Santos M(2), Mendes C(3), Machadinho M(4).

\section{RESUMO}

\section{Introdução}

A população trabalhadora da Europa está a envelhecer e várias organizações definiram concetualmente a categoria dos trabalhadores com mais de 55 anos como os "Trabalhadores Mais Velhos", num contexto onde, a curto/ médio prazo, a sua capacidade produtiva será fundamental para o funcionamento dos diversos países, dado o envelhecimento da população.

\section{Objetivo}

No sentido de perceber quais as implicações que esta mudança poderá ter para a saúde ocupacional, pretende-se: a) caraterizar a população de trabalhadores mais velhos de um município de Portugal no que diz respeito à capacidade para o trabalho; b) comparar uma amostra de trabalhadores mais velhos com outra de trabalhadores com menos de 35 anos.

\section{Método}

Trata-se de um estudo descritivo, correlacional, comparativo de carater transversal, realizado após a aplicação de um inquérito aos trabalhadores do município de Albufeira, com 1301 indivíduos. Para obter a amostra final, utilizou-se o método de amostragem estratificada por idades. O estudo foi autorizado pelos responsáveis do município e a participação dos trabalhadores cumpriu com todos os requisitos éticos.

\section{Resultados}

A amostra de Trabalhadores Mais Velhos é menos escolarizada, tem empregos menos diferenciados e mantem o equilíbrio entre géneros, algo que não acontece nos mais jovens, onde se sente o predomínio do sexo feminino. 
Quando se compara a capacidade laboral observa-se que, no grupo de maior idade, há aumento da morbilidade e da sensação de incapacidade face à doença, bem como um sentimento mais negativo associado à capacidade intrínseca atual, à capacidade face às exigências da tarefa e relativa aos recursos psicológicos disponíveis; acrescenta-se ainda uma taxa superior de absentismo de longa duração e as limitações ao nível da perceção sensorial (visual e auditiva) que afetam a capacidade laboral, fatores que os colocam numa situação de maior vulnerabilidade, face aos Trabalhadores Mais Jovens.

No que diz respeito ao ambiente e relações interpessoais, acreditam que a entidade patronal valoriza menos o seu trabalho em relação aos restantes e são os únicos que referem a existência de ambientes de trabalho maus ou muito maus. Não apresentam, contudo, muitas sugestões de melhoria.

Relativamente à idade que idealizam para a reforma, comprova-se uma relação direta com capacidade para o trabalho (avaliada com o ICT- índice de capacidade para o trabalho) embora pareçam pouco informados acerca das medidas que, potencialmente, poderiam ser facilitadoras e promotoras da sua saúde física, metal e capacidade laboral, tais como um plano de reforma progressiva. Sugerem, no entanto, o aumento do número de férias/ folga como facilitadores.

\section{Conclusão}

A realização do estudo permitiu concluir que existem diferenças estatisticamente significativas em quase todas as áreas analisadas com prejuízo para os Trabalhadores Mais Velhos. É por isso urgente repensar em novas soluções de forma a assegurar no futuro a manutenção da sua capacidade produtiva de uma forma saudável e duradoira.

Palavras-chave: Índice de Capacidade para o Trabalho; Envelhecimento Laboral; Trabalhadores mais velhos; Saúde Ocupacional.

\section{ABSTRACT}

\section{Introduction}

Europe's working population is aging, and a number of organizations have consistently defined the category of workers over 55 as "Older Workers" in a context where, in the short / medium term, their productive capacity will be fundamental for several countries.

\section{Objective}

In order to understand the implications of this change for occupational health, it is intended to: a) characterize the population of older workers in a municipality in Portugal with respect to their capacity for work; b) comparing a sample of older workers with another sample of workers aged less than 35 years.

\section{Method}

This is a descriptive, correlational, comparative cross-sectional study, carried out after the application of a survey of workers in Albufeira municipality, with 1301 individuals. To obtain the final sample, the age-stratified sampling method was used. The study was authorized by the municipal responsible and the workers' participation complied with all ethical requirements. 


\section{Results}

The sample of Older Workers is less educated, has less differentiated jobs and maintains gender balance, something that does not happen in the younger ones where the females are more prevalent.

When comparing work capacity, there is an increase in morbidity and disability in the older age group, as well as a more negative feeling associated with the current intrinsic capacity, the capacity to face the demands of the task, and the available psychological resources. There is also a higher rate of longterm absenteeism and limitations in sensory perception (visual and auditory) that affect work capacity, factors that put them in a situation of greater vulnerability towards the Young Workers.

As far as the environment and interpersonal relationships are concerned, they believe that the employer values less their work than the other rest, and they are the only ones who report the existence of bad or very bad working environments. However, they do not present many suggestions for improvement.

Regarding the idealize retirement age, it exists a direct relationship with work ability (assessed with the WAI- work ability index) although they seem to be poorly informed about measures that could potentially facilitate and promote their physical and mental health, as well as their working capacity. However, they suggest increasing the number of holidays/ days off as facilitators.

\section{Conclusion}

The study concluded that there are statistically significant differences in almost all the areas analyzed, with detriment to older workers. It is therefore urgent to rethink new solutions in order to ensure in the future the maintenance of its productive capacity in a healthy and lasting way.

Key-Words: Work Ability Index; Aging work; Older workers; Occupational Health.

\section{INTRODUÇÃO}

O envelhecimento demográfico não se circunscreve apenas ao aumento da longevidade e do número de pessoas com idade igual ou superior a 65 anos, bem com às suas necessidades específicas. Associado a esse fenómeno está também o envelhecimento da população trabalhadora, fruto da diminuição da taxa de natalidade com consequente diminuição da mão-de-obra laboral disponível (1) o que, em alguns países, poderá ter graves consequências, pois infere-se que, no futuro, poderão não existir jovens suficientes para colmatar as necessidades produtivas atuais ${ }^{(2)}$.

Não há uma definição aceite universalmente para trabalhadores mais velhos (TMV), no entanto, algumas organizações como a Comissão Europeia, o Eurostat e a Organização Internacional do Trabalho, caraterizam-na na categoria de idades entre os 55 e os 64 anos (1). Se analisarmos a evolução da população ativa nos últimos 30 anos (tabela 1), é possível observar a substituição gradual de trabalhadores mais jovens por menos jovens, encontrando-se atualmente a maioria dos trabalhadores (52,2\%) na faixa etária entre os 35 e os 54 anos de idade ${ }^{(3)}$.

Tabela 1- População ativa de Portugal por grupo etário (\%). Diferenças entre 1986 e 2017

\section{Ano Faixa etária}




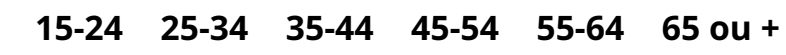

\begin{tabular}{lllllll}
\hline 1986 & 21,5 & 23,7 & 21,6 & 18,5 & 8,8 & 3,4 \\
\hline 2017 & 7,1 & 19,8 & 27,0 & 25,2 & 16,2 & 4,7
\end{tabular}

Fonte: Eurostat | Institutos Nacionais de Estatística, PORDATA, $2018^{\text {(2) }}$

À medida que os trabalhadores envelhecem, surgem alterações que podem afetar a sua capacidade de trabalho, nomeadamente a diminuição das capacidades aeróbica, muscular, termorreguladora, cognitiva e sensitiva (1) (2) (4), fatores que dificultam a concretização das tarefas e a interação social no local de trabalho(1). No entanto, ressalva-se que estas alterações requerem uma avaliação individualizada, pois a performance não se encontra associada diretamente à idade, ou seja, é bem possível que em muitos empregos/ locais os indivíduos mais velhos possam ter uma aptidão superior aos mais jovens ${ }^{(1)}$.

Simultaneamente, com o envelhecimento surgem as doenças crónicas, resultantes essencialmente de estilos de vida menos saudáveis (obesidade, sedentarismo, tabagismo), acompanhadas por patologias associadas ao trabalho (por aumento do tempo de exposição aos fatores de risco laborais), que diminuem a capacidade laboral, implicando maior adaptação às condições de trabalho (incluindo o número de horas de cada turno) e influenciando a decisão de reforma antecipada (1) (2).

No entanto, analisando o relatório do EUROFOUND sobre os trabalhadores europeus mais velhos (1), depreende-se que os principais fatores que os distinguem negativamente dos mais novos são de ordem psicossocial (4) e resultam essencialmente da falta de motivação para trabalhar (1) (2), vulgarmente associada à ausência de perspetivas de evolução na carreira (1) (2), à crença de que têm mais dificuldade em aprender e acompanhar a evolução tecnológica (1) (2), à insatisfação relativa à sua capacidade produtiva (1), à sensação de serem descriminados pelos patrões em relação aos mais novos (1) (2) e à proximidade da idade da reforma que induz uma perceção de incapacidade para trabalhar num curto espaço de tempo (1). Todos estes fatores contribuem para a diminuição da capacidade do trabalhador e consequentemente, da produtividade.

\section{CAPACIDADE PARA O TRABALHO}

A capacidade para o trabalho resulta da equação entre os recursos do trabalhador e as exigências do trabalho e é influenciada pela sua condição sociodemográfica, estilo de vida, estado de saúde e processo de envelhecimento ${ }^{(6)}$. Para a sua avaliação, pode ser operacionalizado o Work Ability Index, que foi estruturado segundo os estudos do Finnish Institute of Occupational Health, sendo depois traduzido e adaptado para Portugal, passando a denominar-se Índice de Capacidade para o Trabalho $(\mathrm{ICT})^{(7)}$.

O ICT é um instrumento de mensuração fácil de usar, rápido e fiável, para ser utilizado pelas equipas de saúde ocupacional, no sentido de identificarem os trabalhadores que necessitam de apoio, por forma a prevenir a diminuição da aptidão laboral (7), através de projetos de promoção da saúde, melhoria das condições laborais e desenvolvimento de competências nos trabalhadores (7) (8); pode ainda ser usado para prever o risco de incapacidade a curto prazo ${ }^{(7)}$. 
Consideram-se como prioritários para intervenção os trabalhadores avaliados com uma capacidade para o trabalho pobre (pontuação máxima 27); seguem-se os de capacidade moderada (pontuação entre 28 e 36), que requerem medidas para ajudar a melhorar a capacidade de trabalho; os que apresentam um bom ICT (pontuação entre 37 e 43), que carecem de instruções sobre como sustentar a sua capacidade para o trabalho; e por último os classificados com um Excelente (44-49), que carecem de ser informados sobre os determinantes facilitadores e dificultadores da sua capacidade para o trabalho ${ }^{(7)}$.

\section{PERSPETIVAS DE MUDANÇA}

O envelhecimento laboral pode ser observado como uma oportunidade, desde que se consiga tornar o trabalho mais sustentável, organizando-o de maneira a atender melhor às necessidades das gerações mais velhas e garantir vidas profissionais mais saudáveis (1).

As principais medidas projetadas, para evitar a reforma antecipada e garantir a produtividade dos TMV, passam por garantir planos de reforma progressiva com redução gradual do número de horas de trabalho (1) (2); adoção de estratégias sustentadas de aconselhamento e reorientação profissional na meia-idade (35-45 anos), promovendo a aquisição de novas competências e a mobilidade laboral de forma a adaptar as condições de trabalho às necessidades e expetativas futuras (1), como, por exemplo, a assunção de cargos de "orientação" face aos funcionários mais novos e inexperientes (2); proporcionar a reconciliação entre o trabalho e as solicitações familiares (que vulgarmente aumentam entre os 50 e os 65 anos, devido à dependência dos familiares mais velhos) ${ }^{(1)}$, possibilitando horários flexíveis, potencialmente intercalados com licenças extensas e trabalho fora das instalações da empresa (2); erradicar a descriminação laboral associada à idade (1) (2), reconhecendo a capacidade laboral dos trabalhadores com mais idade(2); proporcionar serviços de vigilância e promoção da saúde, para evitar o aparecimento ou agravamento de patologias (1), e facilitar a reabilitação dos trabalhadores com problemas de saúde, bem como a sua reintegração no local de trabalho, mantendo o vínculo entre a empresa e o trabalhador ausente por doença (1).

Na Europa, setores como a agricultura, educação, saúde, trabalho social e administração pública são particularmente afetados por este fenómeno ${ }^{(4)}$, pelo que são áreas particularmente vulneráveis que importa estudar, até porque estão mais expostos às consequências dos cortes de gastos públicos atuais e futuros, levando à insegurança no emprego e ao risco de desemprego (4).

Nesse sentido, desenvolveu-se um estudo num município de Portugal de média dimensão, onde o fenómeno do envelhecimento laboral é uma realidade, com o intuito de perceber quais as diferenças entre os TMV e os trabalhadores mais jovens (TMJ), em termos de capacidade para o trabalho, para poder equacionar as soluções que visem o desenvolvimento de um envelhecimento laboral sustentável.

Espera-se que a sua concretização, juntamente com outros estudos equivalentes, seja um contributo para ajudar a repensar em soluções úteis capazes de influenciar as decisões políticas, no sentido de otimizar a saúde dos TMV e, consequentemente, a sua capacidade para o trabalho.

\section{METODOLOGIA}

Trata-se de um estudo descritivo, correlacional, comparativo, de carater transversal. 
A população de funcionários do município é de aproximadamente 1301 indivíduos. Considerando-se um nível de confiança de 95\%, um erro amostral de 5\% estimou-se que seria necessário recolher um total de 297 entrevistas.

Para obter a amostra final, utilizou-se o método de amostragem estratificada por idades como se documenta no quadro 1.

Quadro 1- Calculo da amostra - Amostragem estratificada por idades

\begin{tabular}{lll} 
Faixa etária & População & Amostra \\
\hline 18 a 35 anos & 122 Funcionários & 28 Funcionários \\
\hline 36 a 44 anos & 322 Funcionários & 74 Funcionários \\
\hline 45 a 54 anos & 397 Funcionários & 91 Funcionários \\
\hline 55 a 70 anos & 460 Funcionários & 104 Funcionários \\
\hline Total & 1301 Funcionários & 297 Funcionários
\end{tabular}

No entanto, como se pretendia somente comparar os TMV com os TMJ, foram apenas utilizadas as amostras relativas aos funcionários com idade inferior a 36 e superior a 54 anos.

Os objetivos para efetuar o estudo foram: 1-Comparar as amostras em termos sociodemográficos; 2Comparar a pontuação final e diferentes parâmetros do ICT; 3- Comparar a morbilidade e funcionalidade percecionadas; 4-Comparar as opiniões e sugestões de melhoria relativas ao ambiente laboral; 5-Comparar as expetativas face ao futuro na profissão; 6-Estudar a influência das caraterísticas sociodemográficas nas diferentes variáveis; 7-Estudar as relações entre o ICT e as restantes variáveis.

A recolha de dados ocorreu na presença dos funcionários e teve o seu término em outubro de 2018. Para tal, aplicou-se um questionário que pretendia dar resposta a seis domínios e que permitiu operacionalizar seis variáveis independentes e 37 variáveis dependentes (consultar o quadro 2). Para o domínio sugestões de melhoria, realizou-se a análise qualitativa das respostas para obtenção das variáveis, possibilitando o seu tratamento estatístico posterior.

Quadro 2- Domínios e variáveis em estudo

\begin{tabular}{ll} 
Domínio & Variáveis \\
\hline $\begin{array}{l}\text { Caraterização } \\
\text { socio }\end{array}$ & Idade; Sexo; Estado civil; Escolaridade; Profissão; Categoria profissional \\
demográfica &
\end{tabular}


Índice de

Capacidade

para o

Trabalho
Capacidade para o trabalho atual comparada com o seu melhor; Capacidade para o trabalho em relação às exigências da tarefa; Pontuação relativa ao n. ${ }^{\circ}$ de doenças atuais diagnosticadas pelo médico; Estimativa do grau de incapacidade para o trabalho devido a doença; Absentismo no último ano devido a doenças; Prognóstico da capacidade para o trabalho para daqui a dois anos; Autoavaliação dos recursos psicológicos; Pontuação final no ICT; Necessidade de intervenção

Morbilidade e Número de doenças percecionadas; Perceção sobre a acuidade visual; Perceção sobre a funcionalidade acuidade auditiva

Expectativas Idade estimada para a reforma; Opinião sobre a existência de um sistema de reforma face ao futuro progressiva profissional

Ambiente Relação com a entidade empregadora; Relação com os superiores hierárquicos; laboral Classificação do ambiente laboral; Sugestões de melhoria

Sugestões de Mais luz, melhor contraste; Menos ruído; Melhorar a Climatização; Melhorar as melhoria instalações; Eliminar a rotação de turnos; Eliminar os turnos noturnos; Aumentar as folgas/ férias; Diminuir o tamanho dos turnos; Permitir a jornada contínua; Aumentar as pausas; Aumentar a rotatividade das tarefas; Contratar mais trabalhadores; Renovar o material de trabalho; Redução das tarefas/ Alterar as funções; Organização do trabalho; Melhorar as relações entre colegas; Melhorar as relações com o chefe; Melhorar o salário; Progressão na carreira; Outras

$\mathrm{Na}$ análise descritiva foram utilizadas medidas de tendência central, enquanto na inferencial, para testar as associações, foram aplicados os testes do Qui quadrado e de Fisher (variáveis nominais), testes de Mann-whitney e Kruskal-Wallis (variáveis sem distribuição normal) e teste t para amostras independentes (variáveis com distribuição normal); para averiguar a existência de correlações recorreu-se ao teste Rho de Spearman. A relação entre as variáveis será dada pelo valor de p. Para valores de $p<0.05$ rejeita-se a hipótese nula, ou seja, a probabilidade das diferenças registadas na amostra serem devidas ao acaso é muito pequena. Caso o p>0,05, considera-se que não existe evidência suficiente para rejeitar a hipótese nula. Os dados foram processados com a ajuda do SPSS24.

Os responsáveis pelo município autorizaram a realização do estudo e os funcionários participaram voluntariamente após obtenção do seu consentimento livre e esclarecido.

\section{RESULTADOS}

A amostra trabalhada neste estudo engloba um total 132 funcionários, divididos por dois grupos: os TMJ, com idades inferiores a 36 anos e os TMV, com idades superiores a 54 anos.

\section{CARATERIZAÇÃO SOCIODEMOGRÁFICA}

Na tabela 1 é possível consultar as caraterísticas sociodemográficas da amostra tendo em conta a faixa etária em que os funcionários se enquadram.

Tabela 2- Caraterísticas sociodemográficas dos trabalhadores mais jovens e dos mais velhos 
Variáveis

$\begin{array}{lll}\begin{array}{l}\text { Idade }<35 \\ \text { anos }\end{array} & \begin{array}{l}\text { Idade }>\text { a } 54 \\ \text { anos }\end{array} & \begin{array}{l}\text { Qui-quadrado }\left(X^{2}\right) \text { e Fisher } \\ \text { (LSD) }\end{array}\end{array}$

n $\quad \% \quad$ n

\section{Sexo}

\begin{tabular}{lccccc}
\hline Feminino & 21 & $63,6 \%$ & 51 & $49,0 \%$ & $X^{2}=2,141 ; p=0,143$ \\
\cline { 1 - 4 } Masculino & 12 & $36,4 \%$ & 53 & $51,0 \%$ &
\end{tabular}

\section{Estado civil}

\begin{tabular}{|c|c|c|c|c|c|}
\hline Solteiro & 13 & $39,4 \%$ & 9 & $8,7 \%$ & LSD $=43,646 ; p<0,001$ \\
\hline Casado & 6 & $18,2 \%$ & 66 & $63,5 \%$ & \\
\hline União de facto & 11 & $33,3 \%$ & 6 & $5,8 \%$ & \\
\hline Viúvo & 2 & $6,1 \%$ & 5 & $4,8 \%$ & \\
\hline Separado & 0 & 0 & 2 & $1,9 \%$ & \\
\hline Divorciado & 1 & $3,0 \%$ & 16 & $15,4 \%$ & \\
\hline
\end{tabular}

\section{Nível de escolaridade}

\begin{tabular}{|c|c|c|c|c|c|}
\hline $1^{\circ}$ ciclo básico & 0 & 0 & 42 & $40,4 \%$ & $L S D=65,504 ; p<0,001$ \\
\hline $2^{\circ}$ ciclo básico & 1 & $3,0 \%$ & 11 & $10,6 \%$ & \\
\hline $3^{\circ}$ ciclo básico & 3 & $9,1 \%$ & 34 & $32,7 \%$ & \\
\hline Secundário & 14 & $42,4 \%$ & 14 & $13,5 \%$ & \\
\hline Bacharelato & 0 & 0 & 0 & $0,0 \%$ & \\
\hline Licenciatura & 12 & $36,4 \%$ & 3 & $2,9 \%$ & \\
\hline Mestrado & 3 & $9,1 \%$ & 0 & $0,0 \%$ & \\
\hline
\end{tabular}

\section{Profissão}

\begin{tabular}{llllll} 
Poder legislativo e órgãos executivos & 0 & 0 & 2 & $1,9 \%$ & \multirow{2}{*}{ LSD $=36,017 ; \mathrm{p}<0,001$} \\
\cline { 1 - 5 } Atividades intelectuais e científicas & 12 & $36,4 \%$ & 2 & $1,9 \%$ \\
\hline $\begin{array}{l}\text { Técnicos e profissões de nível } \\
\text { intermédio }\end{array}$ & 6 & $18,2 \%$ & 8 & $7,7 \%$ \\
\hline Pessoal administrativo & 3 & $9,1 \%$ & 9 & $8,7 \%$ \\
\hline Serviços pessoais e segurança & 8 & $24,2 \%$ & 33 & $31,7 \%$ \\
\hline
\end{tabular}




\begin{tabular}{|c|c|c|c|c|}
\hline $\begin{array}{l}\text { Trabalhadores da agricultura e } \\
\text { floresta }\end{array}$ & 1 & $3,0 \%$ & 6 & $5,8 \%$ \\
\hline Indústria, construção e artífices & 0 & 0 & 8 & $7,7 \%$ \\
\hline $\begin{array}{l}\text { Operadores de instalações e } \\
\text { máquinas }\end{array}$ & 0 & 0 & 14 & $13,5 \%$ \\
\hline
\end{tabular}

Trabalhadores não qualificados $\quad 3 \quad 9,1 \% \quad 22 \quad 21,2 \%$

\section{Função exercida}

\begin{tabular}{|c|c|c|c|c|c|}
\hline Assistente operacional & 11 & 33,3 & 92 & $88,5 \%$ & $x^{2}=44,237 ; p<0,001$ \\
\hline \multirow{2}{*}{$\begin{array}{l}\text { Assistente técnico } \\
\text { Técnico superior }\end{array}$} & 10 & 30,3 & \multirow{2}{*}{$\begin{array}{l}9 \\
3\end{array}$} & \multirow{2}{*}{$\begin{array}{l}8,7 \% \\
2,9 \%\end{array}$} & \\
\hline & 12 & 36,4 & & & \\
\hline
\end{tabular}

Na amostra de TMV observa-se um equilíbrio entre sexos, sendo de realçar o predomínio de indivíduos casados ou divorciados, na sua maioria apenas com um dos ciclos de ensino básico completado (83,7\%) e pertencentes, essencialmente, à categoria de assistente operacional $(88,5 \%)$, o que contrasta com a população de TMJ, maioritariamente do sexo feminino, mais escolarizada $(42,4 \%$ ensino secundário; $45,5 \%$ ensino superior), predominantemente solteira $(39,4 \%)$ ou em união de facto $(33,3 \%)$ e que trabalham essencialmente como assistentes técnicos $(30,3 \%)$ ou técnicos superiores $(36,4 \%)$. Perante essa evidência, não é de estranhar que os TMV exerçam profissões de elevada exigência física, como é o caso dos trabalhadores de serviços pessoais, proteção e segurança $(31,7 \%)$, dos trabalhadores não qualificados $(21,2 \%)$ e dos operadores de máquinas e instalações (13,5\%), enquanto os TMJ se dedicam a profissões de elevada exigência mental, onde se enquadram os técnicos superiores $(36,4 \%)$.

\section{ÍNDICE DE CAPACIDADE PARA O TRABALHO EM FUNÇÃO DA IDADE}

Analisando a distribuição dos trabalhadores segundo a classificação do ICT (Gráfico 2), é possível constatar que apenas $15,4 \%$ dos TMV e $3 \%$ dos TMJ mantem preservada a capacidade de trabalho; no patamar seguinte (boa capacidade), estão os trabalhadores que necessitam de medidas de suporte para, no limite, manter a sua capacidade, o que acontece com a maioria dos TMJ $(84,8 \%)$ e quase metade dos TMV (45,2\%).

Gráfico 1- Distribuição dos trabalhadores segundo a pontuação do ICT

Analisando os trabalhadores que carecem de ações de melhoria para aumentar a capacidade laboral (capacidade moderada), os TMV sobressaem $(28,8 \%)$ sobre os TMJ, facto que também acontece no nível mais baixo de capacidade, onde é fundamental tomar medidas no sentido de identificar no trabalhador e/ ou nas suas condições de trabalho, as causas para o problema.

Aplicando o teste t para amostras independentes, observa-se que, em média, os TMJ têm maior capacidade para o trabalho $(39,06 \pm 4,59)$ que os TMV $(37,02 \pm 7,51)$, embora a diferença não seja estatisticamente significativa ( $t=1,872 ; \mathrm{p}=0,064)$. Constata-se, no entanto, que, embora no limite mínimo, os TMV têm em média uma "boa capacidade de trabalho", sem, contudo, deixar de realçar a existência de funcionários ativos com um ICT muito reduzido (12,5 pontos). 
Avaliando a influência dos diferentes fatores do ICT (tabela 3) constata-se que ambos os grupos, em média, autoavaliaram a sua capacidade atual como bastante positiva, embora a aplicação do teste $t$ tenha revelado diferenças estatisticamente significativas entre eles ( $t=2,263 ; p=0,026)$ que apontam para uma autoavaliação menos positiva por parte dos TMV; diferenças semelhantes foram também encontradas relativamente ao $n^{\circ}$ de doenças ( $\left.t=2,648 ; p=0,011\right)$ e à estimativa do grau de incapacidade para o trabalho devido a doença $(t=2,234 ; p=0,029)$ o que evidencia a influência negativa da doença na capacidade de trabalho dos TMV.

Tabela 3- Resultados médios finais dos diferentes itens do Índice de Capacidade para o Trabalho

\begin{tabular}{|c|c|c|c|c|}
\hline & TMJ & TMV & Teste $\mathbf{t}$ & Limites \\
\hline ITENS & Média & & & \\
\hline $\begin{array}{l}\text { ITEM1 - Capacidade para o trabalho atual comparada } \\
\text { com o seu melhor }\end{array}$ & $8,82 \pm 1,16$ & $8,13 \pm 2,29$ & $\begin{array}{l}t= \\
2,263 \\
p=0,026\end{array}$ & $0-10$ \\
\hline $\begin{array}{l}\text { ITEM2 - Capacidade para o trabalho em relação às } \\
\text { exigências da tarefa }\end{array}$ & $8,55 \pm 1,49$ & $8,25 \pm 1,85$ & $\begin{array}{l}\mathrm{t}= \\
0,848 \\
\mathrm{p}=0,398\end{array}$ & $2-10$ \\
\hline $\begin{array}{l}\text { ITEM3 - Pontuação relativa ao } n .^{\circ} \text { de doenças atuais } \\
\text { diagnosticadas pelo médico }\end{array}$ & $4,94 \pm 2,39$ & $3,73 \pm 1,88$ & $\begin{array}{l}t= \\
2,648 \\
p=0,011\end{array}$ & $1-7$ \\
\hline $\begin{array}{l}\text { ITEM4 - Estimativa do grau de incapacidade para o } \\
\text { trabalho devido a doença }\end{array}$ & $4,93 \pm 1,29$ & $4,33 \pm 1,58$ & $\begin{array}{l}t= \\
2,234 ; \\
p=0,029\end{array}$ & $1-6$ \\
\hline ITEM5 - Absentismo no último ano devido a doenças & $3,39 \pm 1,22$ & $3,65 \pm 1,41$ & $\begin{array}{l}\mathrm{t}=- \\
0,949 \\
\mathrm{p}=0,344\end{array}$ & $1-5$ \\
\hline $\begin{array}{l}\text { ITEM6 - Prognóstico da capacidade para o trabalho } \\
\text { para daqui a dois anos }\end{array}$ & $5,09 \pm 1,95$ & $5,67 \pm 2,16$ & $\begin{array}{l}t=- \\
1,376 \\
p=0,171\end{array}$ & $1-7$ \\
\hline ITEM7 - Autoavaliação dos recursos psicológicos & $3,33 \pm 0,64$ & $3,25 \pm 0,81$ & $\begin{array}{l}t= \\
0,475 \\
p=0,635\end{array}$ & $1-4$ \\
\hline Índice de Capacidade para o Trabalho & $39,06 \pm 4,59$ & $37,02 \pm 7,51$ & $\begin{array}{l}t= \\
1,872 ; \\
p=0,064\end{array}$ & 7-49 \\
\hline
\end{tabular}

É de realçar ainda o elevado absentismo em ambos os grupos e, apesar de as diferenças não serem estatisticamente significativas, os TMJ faltaram, em média, mais vezes $(3,39 \pm 1,22)$ do que os TMV $(3,65 \pm 1,41)$. De igual modo, são também os TMJ os que se sentem menos capazes para permanecer no mesmo posto de trabalho por dois ou mais anos. 
Por último, analisando a autoperceção sobre os recursos psicológicos, ambos os grupos se avaliam muito positivamente e, apesar de os TMJ apresentarem uma pontuação superior, as diferenças não são estatisticamente significativas.

Simultaneamente, analisou-se a existência de correlações entre os diferentes itens e a pontuação final do ICT (tabela 4) no sentido de identificar qual(ais) influencia $(m)$ mais o resultado.

Tabela 4- Correlações entre o ICT e os restantes itens da escala

\begin{tabular}{|c|c|c|c|c|c|c|c|c|}
\hline & & $\begin{array}{l}\text { Capacidade } \\
\text { de trabalho } \\
\text { atual }\end{array}$ & $\begin{array}{l}\text { Capacidade } \\
\text { relativa às } \\
\text { exigências }\end{array}$ & $\begin{array}{l}\text { Pontuação } \\
\text { atribuída } \\
\text { às } \\
\text { doenças }\end{array}$ & $\begin{array}{l}\text { A doença } \\
\text { limita o } \\
\text { trabalho? }\end{array}$ & $\begin{array}{l}\text { Absentismo } \\
\text { no último } \\
\text { ano }\end{array}$ & $\begin{array}{l}\text { Trabalho } \\
\text { daqui a } \\
\text { dois } \\
\text { anos }\end{array}$ & $\begin{array}{l}\text { Recursos } \\
\text { psicológicos } \\
\text { no dia-a-dia }\end{array}$ \\
\hline ICT & Coef & 0,628 & 0,723 & 0,555 & 0,689 & 0,435 & 0,423 & 0,434 \\
\hline TMV & $p$ & 0,000 & 0,000 & 0,000 & 0,000 & 0,000 & 0,000 & 0,000 \\
\hline ICT & Coef & 0,538 & 0,398 & 0,166 & 0,293 & 0,219 & 0,580 & 0,275 \\
\hline TMJ & $p$ & 0,001 & 0,022 & 0,356 & 0,097 & 0,221 & 0,000 & 0,122 \\
\hline
\end{tabular}

A aplicação do teste de Spearman revelou que nos TMV todos os itens se relacionam estatisticamente com a pontuação final do ICT, sendo a força de correlação moderada ou forte. No entanto, constata-se que a crença de ter uma doença funcionalmente limitante é o fator que mais influencia negativamente, seguido do número de doenças; enquanto a crença na capacidade individual para fazer face às exigências da tarefa, seguida da crença na capacidade atual são os dois itens que mais contribuem pela positiva.

Relativamente aos TMJ a crença na capacidade atual de trabalho bem como a capacidade relativa face às exigências da tarefa emergem como os fatores que mais contribuem para uma avaliação positiva sobre a capacidade de trabalho, à semelhança dos TMV, enquanto a incapacidade demonstrada para permanecer no mesmo posto de trabalho ao fim de dois anos se afigura como o item mais negativo (tabela 4).

\section{INFLUÊNCIA DAS CARATERÍSTICAS PESSOAIS NA CAPACIDADE PARA O TRABALHO}

Neste ponto analisam-se as caraterísticas pessoais dos TMV e TMJ em função da pontuação obtida no ICT (tabela 5).

Nos TMJ observam-se diferenças estatisticamente significativas ao nível da escolaridade, como demonstra o teste de Kruskal-Wallis $(H=7,093 ; p=0,029)$, sendo possível constatar que, nesta faixa etária, os trabalhadores mais escolarizados apresentam valores superiores de ICT, facto também corroborado pelo teste de Spearman, que comprova a correlação positiva e moderada entre as variáveis ( $r=0,433 ; p=0,012)$. Não se observam quaisquer outras relações estatisticamente relevantes.

Tabela 5- Relações entre as caraterísticas pessoais e a capacidade para o trabalho 


\begin{tabular}{|c|c|c|c|c|}
\hline \multirow[b]{2}{*}{ Sexo } & \multicolumn{2}{|c|}{ Idade $<35$ anos } & \multicolumn{2}{|c|}{ Idade $>$ a 54 anos } \\
\hline & $\begin{array}{l}\text { Posto } \\
\text { médio }\end{array}$ & $\begin{array}{l}\text { U de Mann- } \\
\text { Whitney }\end{array}$ & $\begin{array}{l}\text { Posto } \\
\text { médio }\end{array}$ & $\begin{array}{l}\text { U de Mann- } \\
\text { Whitney }\end{array}$ \\
\hline Feminino & 16,88 & \multirow{2}{*}{$\begin{array}{l}(U=123,500 \\
p=0,881)\end{array}$} & 46,26 & \multirow{2}{*}{$\begin{array}{l}(U=1033,500 \\
p=0,027)\end{array}$} \\
\hline Masculino & 17,21 & & \multirow{2}{*}{\multicolumn{2}{|c|}{ Teste Exato }} \\
\hline Estado civil & \multicolumn{2}{|c|}{ Teste Exato de Fisher } & & \\
\hline Solteiro & \multicolumn{2}{|c|}{$(\mathrm{LSD}=16,770 ; p=0,232)$} & \multicolumn{2}{|c|}{$(L S D=16,012 ; p=0,238)$} \\
\hline \multicolumn{5}{|l|}{ Casado } \\
\hline \multicolumn{5}{|l|}{ União de facto } \\
\hline \multicolumn{5}{|l|}{ Viúvo } \\
\hline \multicolumn{5}{|l|}{ Separado } \\
\hline \multicolumn{5}{|l|}{ Divorciado } \\
\hline Nível de escolaridade & $\begin{array}{l}\text { Posto } \\
\text { médio }\end{array}$ & Kruskal-Wallis & $\begin{array}{l}\text { Posto } \\
\text { médio }\end{array}$ & Kruskal-Wallis \\
\hline Ensino básico & 10,75 & \multirow{3}{*}{$\begin{array}{l}(H=7,093 \\
p=0,029)\end{array}$} & 52,22 & \multirow[t]{3}{*}{$(H=0,067 ; p=0,967)$} \\
\hline Ensino secundário & 16,14 & & 53,50 & \\
\hline Ensino superior & 19,47 & & 55,83 & \\
\hline Profissão & $\begin{array}{l}\text { Posto } \\
\text { médio }\end{array}$ & Kruskal-Wallis & $\begin{array}{l}\text { Posto } \\
\text { médio }\end{array}$ & Kruskal-Wallis \\
\hline $\begin{array}{l}\text { Poder legislativo e órgãos } \\
\text { executivos }\end{array}$ & 0,00 & \multirow[t]{8}{*}{$\begin{array}{l}(H=7,827 \\
p=0,166)\end{array}$} & 45.75 & \multirow[t]{8}{*}{$(H=9,271 ; p=0,320)$} \\
\hline Atividades intelectuais e científicas & 18,42 & & 35.50 & \\
\hline $\begin{array}{l}\text { Técnicos e profissões de nível } \\
\text { intermédio }\end{array}$ & 18,50 & & 60.19 & \\
\hline Pessoal administrativo & 13,33 & & 40.28 & \\
\hline Serviços pessoais e segurança & 16,31 & & 51.58 & \\
\hline $\begin{array}{l}\text { Trabalhadores da agricultura e } \\
\text { floresta }\end{array}$ & 3,00 & & 56.25 & \\
\hline Indústria, construção e artífices & 0,00 & & 58.44 & \\
\hline $\begin{array}{l}\text { Operadores de instalações e } \\
\text { máquinas }\end{array}$ & 0,00 & & 68.00 & \\
\hline
\end{tabular}




\begin{tabular}{|c|c|c|c|c|}
\hline Trabalhadores não qualificados & 18,50 & & 45.20 & \\
\hline Função exercida & $\begin{array}{l}\text { Posto } \\
\text { médio }\end{array}$ & Kruskal-Wallis & $\begin{array}{l}\text { Posto } \\
\text { médio }\end{array}$ & Kruskal-Wallis \\
\hline Assistente operacional & 17.09 & \multirow{3}{*}{$\begin{array}{l}(H=1,557 ; \\
p=0,459)\end{array}$} & 53.07 & \multirow[t]{3}{*}{$(H=0,612 ; p=0,736)$} \\
\hline \multirow{2}{*}{$\begin{array}{l}\text { Assistente técnico } \\
\text { Técnico superior }\end{array}$} & 15.20 & & 45.61 & \\
\hline & 18.42 & & 55.83 & \\
\hline
\end{tabular}

Relativamente à população de TMV constata-se apenas a existência de diferenças estatisticamente significativas relativamente ao sexo, ou seja, o teste de Mann-Whitney revelou que os trabalhadores do sexo masculino apresentam valores de ICT superiores aos do sexo feminino, sendo as diferenças estatisticamente significativas $(U=1033,500 ; p=0,027)$.

\section{PERCEÇÃO INDIVIDUAL SOBRE A EXIGÊNCIA DA ATIVIDADE E CAPACIDADE PARA O TRABALHO}

Os trabalhadores foram convidados a pronunciar-se sobre se a principal exigência da sua atividade era mental, física ou ambas (gráfico 2). Surpreendentemente, apenas uma pequena amostra $(5,1 \%)$ referiu a carga física, seguindo-se a mental (13,8\%), optando a grande maioria por nomear ambas $(81,1 \%)$.

Gráfico 2- Principais exigências da atividade segundo a faixa etária dos trabalhadores

Analisando a distribuição das respostas dadas pelos TMJ e TMV, através da aplicação do teste de Fisher, conclui-se que as diferenças entre grupos não são estatisticamente significativas $\left(X^{2}=0,431\right.$; $p=0,787)$, ou seja, a perceção individual sobre a exigência da atividade laboral é semelhante em ambos os grupos.

Considerando as variáveis sociodemográficas, constata-se a existência de diferenças estatisticamente significativas $\left(X^{2}=13,098 ; p=0,047\right)$ ao nível da escolaridade nos TMV, que indicam que os menos escolarizados referem exercer atividades de elevada exigência física, enquanto os que têm maior formação académica referem elevada exigência mental.

Nos TMV observam-se ainda diferenças estatísticas relevantes ao nível da profissão ( $X^{2}=36,688$; $p<0,001)$, donde se destacam em termos de exigências mentais os trabalhadores que exercem órgãos executivos, os especialistas em atividades científicas, os técnicos de nível intermédio e o pessoal administrativo; com elevada exigência física, emergem os jardineiros e os profissionais não qualificados.

Por último, também nos TMV, constatam-se diferenças estatisticamente relevantes na categoria profissional $\left(X^{2}=17,544 ; p=0,001\right)$, estando a exigência física associada aos assistentes operacionais e a mental aos assistentes técnicos e técnicos superiores.

Não se identificam mais diferenças relevantes nas restantes variáveis sociodemográficas quer para os TMJ como para os TMV.

Por último, ao investigar a relação entre os valores do ICT e a perceção individual sobre a exigência laboral, foi possível identificar, através do teste de Kruskal-Wallis, que não existem diferenças 
estatísticas relevantes entre os TMJ $(H=1,579 ; p=0,454)$ ou entre os TMV $(H=1,730 ; p=0,421)$, concluindo-se que a perceção individual acerca da principal exigência do trabalho não tem influência relevante na pontuação do índice de capacidade para o trabalho.

\section{NÚMERO DE DOENÇAS E CAPACIDADE PARA O TRABALHO}

O número médio de doenças nos TMV foi de $2,46 \pm 1,78$, variando entre a ausência de qualquer doença (apenas 13,5\% da amostra) e a coexistência de sete patologias em simultâneo (em 1,9\% dos TMV), enquanto nos TMJ, a média foi de 1,58 11,95, verificando-se que a maioria (51,5\%) não apresentava qualquer doença. Analisando as diferenças, o teste T permite concluir com significância estatística ( $\mathrm{t}=$ 2,$429 ; p=0,016$ ) que os TMV apresentam mais patologias que os TMJ.

Considerando as variáveis sociodemográficas constata-se apenas a existência de diferenças estatisticamente significativas nos TMJ relativamente ao sexo $(U=50000 ; p=0,002)$ e à escolaridade $(H=8,348 ; p=0,038)$, revelando que nesta faixa etária os trabalhadores do sexo masculino, bem como os que têm apenas um dos níveis de ensino básico, apresentam consideravelmente um maior número de doenças; nos TMV contudo, não se registam diferenças estatísticas relevantes.

Finalmente, analisando a influência da multimorbilidade sobre a capacidade para o trabalho, constatase que apesar de não existirem diferenças estatisticamente relevantes nos TMJ $(H=3,284 ; p=0,350)$, 0 mesmo não acontece nos TMV $(H=29,208 ; \mathrm{p}<0,001)$, revelando que os trabalhadores que apresentam mais doenças, têm menor capacidade para trabalhar, facto comprovado pelo teste de correlação de Spearman $(r=-0,559 ; p<0,001)$.

\section{PERCEÇÃO SENSORIAL (VISÃO E AUDIÇÃO) E A CAPACIDADE PARA O TRABALHO}

A grande maioria dos TMJ $(78,8 \%)$ e TMV $(77,9 \%)$ consideram manter a acuidade visual adequada para exercer a sua atividade profissional (tabela 6); quando questionados se ao longo dos anos de trabalho percecionaram alterações na acuidade visual decorrentes dessa atividade, a resposta em ambos os grupos foi maioritariamente não (81,8\% e 76,9\% respetivamente).

Tabela 6- Perceção dos trabalhadores acerca da auidade visual e auditiva (\%)

\begin{tabular}{|c|c|c|c|c|c|c|c|c|}
\hline & \multicolumn{4}{|c|}{ Acuidade visual } & \multicolumn{4}{|c|}{ Acuidade auditiva } \\
\hline & \multicolumn{2}{|c|}{$\begin{array}{l}\text { Adequada para a } \\
\text { atividade laboral }\end{array}$} & \multicolumn{2}{|c|}{$\begin{array}{l}\text { Alteração ao longo } \\
\text { dos anos }\end{array}$} & \multicolumn{2}{|c|}{$\begin{array}{l}\text { Adequada para a } \\
\text { atividade laboral }\end{array}$} & \multicolumn{2}{|c|}{$\begin{array}{l}\text { Alteração ao longo } \\
\text { dos anos }\end{array}$} \\
\hline & Sim & Não & Está igual & Está pior & Sim & Não & Está igual & Está pior \\
\hline TMJ & 78,8 & 21,2 & 81,8 & 18,2 & 90,9 & 9,1 & 57,6 & 42,4 \\
\hline TMV & 77,9 & 22,1 & 76,9 & 23,1 & 82,7 & 17,3 & 73,1 & 26,9 \\
\hline
\end{tabular}

Uma elevada percentagem de TMJ $(90,9 \%)$ e TMV $(82,7)$ considera ainda que a sua acuidade auditiva se mantém adequada para as exigências do trabalho, no entanto, é de realçar que quase metade dos TMJ $(42,4 \%)$ referem perda de funcionalidade a este nível com o decorrer dos anos, facto menos referenciado pelos TMV (26,9\%).

Analisando as diferenças entre os dois grupos de trabalhadores conclui-se, com a aplicação do teste de 
qui quadrado, que não existem diferenças estatísticas significativas em nenhuma das quatro variáveis: perceção sobre a capacidade visual $\left(X^{2}=0,012 ; p=0,930\right)$ e auditiva $\left(X^{2}=1,303 ; p=0,254\right)$, alterações graduais na visão $\left(X^{2}=1,303 ; p=0,254\right)$ e audição $\left(X^{2}=2,832 ; p=0,128\right)$. 0 mesmo acontece relativamente aos diversos fatores sociodemográficos.

Por último, ao estudar as relações entre a pontuação do ICT e a perceção individual sobre a capacidade visual observa-se, após a aplicação do Teste Mann-Whitney, que quem refere ver mal apresenta valores inferiores no ICT. Essa diferença é estatisticamente significativa nos TMV $(U=592,500 ; p=0,008)$, embora não o seja nos TMJ $(U=50,000 ; p=0,074)$. O mesmo não acontece com a perceção de agravamento ao longo dos anos de trabalho onde as diferenças entre grupos relativas à pontuação do ICT não são estatisticamente relevantes.

À semelhança da acuidade visual, na audição o cenário repete-se, observando-se diferenças estatisticamente significativas nos TMV ( $U=532,000 ; p=0,027)$ e não nos TMJ $(U=32,000 ; p=0,453)$, ou seja, no TMV, a perceção de perda auditiva está estatisticamente associada aos indivíduos que apresentam os valores mais baixos de ICT. Observam-se, no entanto, diferenças relativas à visão no que diz respeito à perceção de perda ao longo dos anos, uma vez que também aqui, apesar de não existirem diferenças relevantes nos TMJ $(U=120,000 ; p=0,653)$, identifica-se, nos TMV, uma associação estatisticamente significativa entre a perceção de perda e o resultado obtido no ICT (U=776,500; $p=0,025)$, ou seja, os trabalhadores que referem que a sua audição piorou ao longo dos anos têm valores de ICT inferiores aos dos que referem que a acuidade auditiva se mantém igual.

\section{IDADE IDEALIZADA PARA A REFORMA E A CAPACIDADE PARA O TRABALHO}

Na tabela 7 é possível constatar que os TMJ anseiam por uma idade de reforma inferior à que é referenciada pelos TMV, sendo de realçar que pelo menos 25\% dos TMJ refere os 55 anos e cerca de metade, no máximo os 60 anos como a idade ideal para se reformarem.

Tabela 7- Idade idealizada para a reforma

\begin{tabular}{|c|c|c|c|}
\hline & & TMJ & TMV \\
\hline Média & & 60.48 & 62.85 \\
\hline Mediana & & 60.00 & 65.00 \\
\hline Moda & & 55 & 66 \\
\hline Mínimo & & 50 & 52 \\
\hline Máximo & & 80 & 70 \\
\hline \multirow[t]{3}{*}{ Percentis } & 25 & 55.00 & 60.00 \\
\hline & 50 & 60.00 & 65.00 \\
\hline & 75 & 65.00 & 66.00 \\
\hline
\end{tabular}


Analisando estatisticamente as diferenças entre os dois grupos etários constata-se que, em média, a idade idealizada para a reforma é inferior nos TMJ $(M=60,48 \pm 6,1)$, do que nos TMV $(M=62,85 \pm 3,8)$ e a diferença é estatisticamente significativa $(t=-2,104 ; p=0,042)$.

Relacionando este fator com as restantes variáveis sociodemográficas constata-se que estas não influenciam significativamente a escolha individual relativa à idade da reforma (tabela 8).

Tabela 8- Relação estatística entre a idade percecionada para a reforma e as variáveis sociodemográficas

\begin{tabular}{|c|c|c|}
\hline Variáveis & Resultado dos testes & estatísticos \\
\hline & TMJ & TMV \\
\hline Sexo & $U^{*}=120,5 ; p=0,839$ & $U^{*}=1252,5 ; p=0,500$ \\
\hline Estado civil & $H^{* *}=3,476 ; p=0,482$ & $H^{* *}=3,744 ; p=0,587$ \\
\hline Escolaridade & $H^{* *}=1,533 ; p=0,675$ & $H^{* *}=3,444 ; p=0,486$ \\
\hline Profissão & $H^{* *}=2,014 ; p=0,733$ & $H^{* *}=5,018 ; p=0,542$ \\
\hline Categoria profissional & $H^{* *}=0,711 ; p=0,701$ & $H^{* *}=1,627 ; p=0,443$ \\
\hline * Teste Mann-Whitney; & ** Teste Kruskal-Wa & \\
\hline $\begin{array}{l}\text { Avaliou-se ainda se exis } \\
\text { ICT. Os resultados indic } \\
\text { entre as variáveis ( } r=0 \text {, } \\
(r=0,276 ; p=0,005) \text {, ou s } \\
\text { pontuação no ICT. }\end{array}$ & $\begin{array}{l}\text { stia correlação estat } \\
\text { cam que, enquanto } \\
, 068 ; p=0,708) \text {, nos } \\
\text { eja, a idade idealizac }\end{array}$ & $\begin{array}{l}\text { Ística entre a idade i } \\
\text { hos TMJ não existe cc } \\
\text { TMV ela está preser } \\
\text { la para a reforma se }\end{array}$ \\
\hline
\end{tabular}

\section{POSSIBILIDADE DE REFORMA PROGRESSIVA E A CAPACIDADE PARA O TRABALHO}

Os trabalhadores foram questionados acerca da hipótese de terem acesso a um plano de reforma progressiva (tabela 9). Observam-se diferenças estatisticamente significativas $\left(X^{2}=24,347 ; p<0,001\right)$ entre os TMJ e os TMV, uma vez que $97 \%$ dos TMJ discorda dessa possibilidade, o que contrasta com os $51,9 \%$ de respostas negativas dadas pelos TMV.

Tabela 9- Opinião sobre o acesso a um plano de reforma progressiva

\begin{tabular}{lcc}
$\begin{array}{l}\text { Gostava que a legislação portuguesa permitisse o acesso a um plano de reforma } \\
\text { progressiva? }\end{array}$ & TMJ & TMV \\
\hline Sim & 3.0 & 40.4 \\
\hline Talvez & 0.0 & 7.7 \\
\hline Não & 97.0 & 51.9
\end{tabular}


Relacionando com as restantes variáveis sociodemográficas constata-se que não existem diferenças estatísticas significativas nos TMJ, uma vez que a grande maioria respondeu negativamente; no entanto, é possível identificar algumas diferenças nos TMV (tabela 10).

Tabela 10- Opinião sobre a reforma progressiva em função das variáveis sociodemográficas

\begin{tabular}{lll} 
Variáveis sociodemográficas & \multicolumn{2}{l}{ Resultado do Teste Exato de Fisher } \\
\cline { 2 - 3 } & TMJ & TMV \\
\hline Sexo & $L S D=1,805 ; p=0,364$ & $L S D=23,283 ; p<0,001$ \\
\hline Estado civil & $L S D=6,216 ; p=0,266$ & $L S D=11,830 ; p=0,205$ \\
\hline Escolaridade & $L S D=4,648 ; p=1,000$ & $L S D=27,742 ; p<0,001$ \\
\hline Profissão & $L S D=8,186 ; p=0,212$ & $L S D=27,571 ; p=0,008$ \\
\hline Categoria profissional & $L S D=1,887 ; p=0,631$ & $L S D=6,510 ; p=0,112$
\end{tabular}

As diferenças encontradas nos TMV devem-se essencialmente a:

1. Sexo - $62,6 \%$ dos homens consideram que a reforma progressiva devia ser uma opção configurada em lei, o que contrasta com os $17,6 \%$ de mulheres que responderam afirmativamente.

2. Escolaridade - $69,1 \%$ dos trabalhadores com o $1^{\circ}$ ciclo de ensino básico considera a reforma progressiva como uma opção válida, enquanto em sentido oposto, nenhum dos trabalhadores licenciados considera importante.

3. Profissão - $87,5 \%$ dos técnicos e profissões de nível intermédio e $50 \%$ dos trabalhadores não qualificados está de acordo com a medida, enquanto nenhum dos especialistas em atividades científicas ou dos representantes de órgãos executivos o fez de forma positiva.

Finalmente, analisando se a opinião acerca da existência de um plano progressivo de reforma configurado em lei é influenciada pela pontuação obtida no ICT, conclui-se a inexistência de diferenças estatísticas significativas quer para os TMJ $(H=0,064 ; p=0,801)$ como para os TMV $(H=2,191 ; p=0,334)$.

\section{VALORIZAÇÃO POR PARTE DO EMPREGADOR E A CAPACIDADE PARA O TRABALHO}

Os trabalhadores foram questionados se atualmente sentiam que o seu trabalho era valorizado por parte da entidade empregadora. A aplicação do teste de Qui-quadrado permite concluir que existe diferenças estatisticamente significativas $\left(X^{2}=16,203 ; p<0,001\right)$ entre a perceção dos TMJ e a dos TMV. Isso é visível no gráfico 3 onde, comparativamente a alguns anos atrás, a maioria dos TMJ (60,6\%) referem sentir-se mais valorizados, facto que contrasta com os TMV, em que apenas 23,2\% mantem esse sentimento.

Relativamente à influência das restantes variáveis sociodemográficas, não se identificaram quaisquer relações estatisticamente significativas com a perceção individual acerca da valorização dada por parte da entidade empregadora. 
Avaliou-se também a existência de relação estatística entre a perceção individual relativa à valorização profissional demonstrada pelo empregador e o valor do ICT. O teste de Kruskal-Wallis permite concluir que não existem associações estatisticamente significativas entre as variáveis, quer para os TMJ $(H=0,680 ; p=0,712)$ como para os TMV $(H=2,073 ; p=0,354)$.

Gráfico 3- Sentimento relativo à valorização profissional dada pela entidade patronal

\section{VALORIZAÇÃO POR PARTE DAS CHEFIAS E CAPACIDADE PARA O TRABALHO}

Os trabalhadores também foram questionados se atualmente sentiam que o seu trabalho era valorizado por parte dos seus superiores hierárquicos. A aplicação do teste de Qui-quadrado permite concluir que não existem diferenças estatisticamente significativas $\left(X^{2}=2,401 ; p=0,301\right)$ entre a perceção dos TMJ e a dos TMV, embora a consulta do gráfico 4 sugira uma ligeira perceção mais positiva por parte dos TMJ.

Gráfico 4- Sentimento relativo à valorização profissional dada pelos superiores hierárquicos

À semelhança do parâmetro anterior, também aqui não se identificaram quaisquer relações estatisticamente significativas entre as diferentes variáveis sociodemográficas e a perceção individual acerca da valorização dada por parte dos superiores hierárquicos.

Relacionando com o valor do ICT, a aplicação do teste de Kruskal-Wallis comprova também a inexistência de diferenças estatisticamente significativas quer entre os TMJ $(H=5,774 ; p=0,056)$, como entre os TMV $(H=0.037 ; p=0,981)$, ou seja, a perceção que os trabalhadores têm sobre a opinião pessoal dos seus superiores hierárquicos acerca do seu trabalho, não influencia significativamente a capacidade para o trabalho.

\section{AMBIENTE LABORAL E A CAPACIDADE PARA O TRABALHO}

Os trabalhadores foram convidados a classificar o seu ambiente de trabalho segundo uma escala de likert de cinco pontos (de "Muito mau" a "Muito bom"). A grande maioria classificou-o como facilitador para a realização das atividades, embora pela consulta do gráfico 5 se perceba que os TMJ percecionam de uma forma mais positiva o seu ambiente laboral. A realização do teste de Fisher permitiu concluir que essa diferença é estatisticamente significativa $\left(X^{2}=19,653 ; p=0,001\right)$

Gráfico 5- Perceção acerca do ambiente de trabalho

A análise de Qui-quadrado não revelou quaisquer relações estatísticas relevantes entre a perceção sobre o ambiente laboral e os diversos fatores sociodemográficos, quer para o grupo dos TMJ como para os TMV.

Apesar de não existirem diferenças estatisticamente significativas nos TMJ $(H=4,061 ; p=0,131)$ quando analisada a relação entre a perceção sobre o ambiente laboral e o valor do ICT, o mesmo não acontece nos TMV (H=9,722; $\mathrm{p}=0,045)$, confirmando a associação entre a existência de ambientes de trabalho classificados como muito maus e a fraca performance no ICT.

\section{FATORES A MUDAR NO LOCAL DE TRABALHO E A CAPACIDADE PARA O TRABALHO}


Os participantes foram convidados a pronunciar-se sobre o potencial conjunto de mudanças que deveriam ser implementadas nos locais de trabalho para melhorar o desempenho profissional. $\mathrm{Na}$ tabela 11 podem ser consultadas todas as sugestões propostas pelos trabalhadores, divididas por cinco categorias - espaço físico; horário laboral; organização do trabalho; relações interpessoais e desenvolvimento profissional.

Tabela 11- Sugestões de melhoria para o local de trabalho

\begin{tabular}{|c|c|c|c|c|c|}
\hline \multirow[t]{2}{*}{ Agregação das sugestões } & \multirow[t]{2}{*}{ Sugestão de melhoria } & \multicolumn{2}{|l|}{ Sim } & \multicolumn{2}{|l|}{ Não } \\
\hline & & TMJ(\%) & $\operatorname{TMV}(\%)$ & TMJ(\%) & $\operatorname{TMV}(\%)$ \\
\hline \multirow{4}{*}{$\begin{array}{l}\text { Melhoria do espaço de } \\
\text { trabalho }\end{array}$} & Mais luz, melhor contraste & 12.1 & 2.9 & 87.9 & 97.1 \\
\hline & Menos ruído & 15.2 & 18.3 & 84.8 & 81.7 \\
\hline & Melhorar a Climatização & 45.5 & 1.9 & 54.5 & 98.1 \\
\hline & Melhorar as instalações & 24.2 & 1.9 & 75.8 & 98.1 \\
\hline \multirow{6}{*}{$\begin{array}{l}\text { Gestão dos horários de } \\
\text { trabalho }\end{array}$} & Eliminar a rotação de turnos & 3.0 & 1.0 & 97.0 & 99.0 \\
\hline & Eliminar os turnos noturnos & 3.0 & 1.0 & 97.0 & 99.0 \\
\hline & Aumentar as folgas/ férias & 36.4 & 50.0 & 63.6 & 50.0 \\
\hline & Diminuir o tamanho dos turnos & 3.0 & 2.9 & 97.0 & 97.1 \\
\hline & Permitir a jornada contínua & 9.1 & 1.9 & 90.9 & 98.1 \\
\hline & Aumentar as pausas & 3.0 & 1.0 & 97.0 & 99.0 \\
\hline \multirow{5}{*}{$\begin{array}{l}\text { Organização da atividade } \\
\text { laboral }\end{array}$} & Aumentar a rotatividade das tarefas & 9.1 & 3.8 & 90.9 & 96.2 \\
\hline & Contratar mais trabalhadores & 9.1 & 7.7 & 90.9 & 92.3 \\
\hline & Renovar o material de trabalho & 0.0 & 6.7 & 100.0 & 93.3 \\
\hline & $\begin{array}{l}\text { Redução das tarefas/ Alterar as } \\
\text { funções }\end{array}$ & 3.0 & 2.9 & 97.0 & 97.1 \\
\hline & Organização do trabalho & 6.1 & 0.0 & 93.9 & 100 \\
\hline \multirow{2}{*}{$\begin{array}{l}\text { Melhoria das relações } \\
\text { pessoais }\end{array}$} & Melhorar as relações entre colegas & 3.0 & 7.7 & 97.0 & 92.3 \\
\hline & Melhorar as relações com o chefe & 12.1 & 8.7 & 87.9 & 91.3 \\
\hline \multirow[t]{2}{*}{ Desenvolvimento profissional } & Melhorar o salário & 6.1 & 2.9 & 93.9 & 97.1 \\
\hline & Progressão na carreira & 0.0 & 2.9 & 100.0 & 97.1 \\
\hline Outros & & 6.1 & 0.0 & 93.9 & 100 \\
\hline
\end{tabular}


Relativamente ao espaço físico laboral existem diferenças estatisticamente significativas, entre os TMJ e os TMV, ao nível da "climatização dos espaços" ( $\left.X^{2}=0,565 ; p<0,001\right)$, da "melhoria das instalações" $\left(X^{2}=\right.$ 0,367; $p<0,001)$ e da "luminosidade" ( $\left.X^{2}=0,179 ; p=0,036\right)$, vistas pelos TMJ como prioritárias para 0 aumento do desempenho profissional. Apesar de entre os grupos, não existirem diferenças relevantes relativas ao "ruído" ( $\left.X^{2}=-0,035 ; p=0,681\right)$, realça-se o número de trabalhadores $(n=24)$ que o referiu como ponto a melhorar de futuro.

Analisando as diversas sugestões para melhorar a gestão ao nível dos horários de trabalho, não se verificam diferenças estatisticamente significativas entre os TMJ e os TMV. Realçam-se apenas as opções de "realizar jornada contínud" ( $X^{2}=0,163$; $\left.p=0,056\right)$, maioritariamente referenciada pelos TMJ, bem como o "aumento de folgas/ férias", amplamente sugerido por 67 trabalhadores de ambos os grupos.

A organização da atividade laboral registou apenas uma sugestão de melhoria - " melhorar a dinâmica laboral" - cuja diferença entre grupos foi estatisticamente significativa $\left(X^{2}=0,216 ; p=0,011\right)$, revelando que os TMJ são os mais inconformados. Nas restantes sugestões, embora não se tenham registado diferenças estatísticas de relevo, a "contratação de mais trabalhadores" $\left(X^{2}=0,022 ; p=0,797\right)$ merece destaque para ambos os grupos, sendo referenciado por 11 indivíduos no total, bem como a "aquisição de material adequado para trabalhar" $\left(X^{2}=-0,131 ; p=0,126\right)$, reclamado apenas pelos TMV.

Nas relações interpessoais também não se observam diferenças estatisticamente significativas entre os TMJ e os TMV; no entanto, sublinha-se a sugestão de "melhoria na relação entre os trabalhadores e os seus superiores hierárquicos" $\left(\mathrm{X}^{2}=0,051 ; \mathrm{p}=0,554\right)$, referenciada por 13 indivíduos da amostra.

No desenvolvimento profissional as sugestões foram muito reduzidas, não sendo visíveis diferenças estatísticas relevantes, nem a evidência de necessidades de melhoria.

Por último, os TMJ apresentaram outras sugestões de melhoria, embora de forma insipiente.

Analisando a relação com os fatores sociodemográficos, apenas foi possível estudar estatisticamente a sugestão - "aumentar ao número de folgas/ férias", devido à fraca expressividade das respostas nas restantes variáveis; não se observam, contudo, diferenças estatisticamente significativas entre os TMJ e os TMV.

Para estudar se a pontuação obtida no ICT está relacionada estatisticamente com alguma das sugestões apresentadas, aplicou-se o teste de Mann-Whitney (tabela 12).

Tabela 12- Relação entre a pontuação do ICT e as sugestões de melhoria

\begin{tabular}{llll} 
Agregação das sugestões & Sugestão de melhoria & \multicolumn{2}{l}{ Teste Mann-Whitney } \\
\cline { 3 - 4 } & & TMJ & TMV \\
\hline $\begin{array}{l}\text { Melhoria do espaço de } \\
\text { trabalho }\end{array}$ & Mais luz, melhor contraste & $\begin{array}{l}(U=52,000 ; \\
p=0,770)\end{array}$ & $\begin{array}{l}(U=121,000 ; \\
p=0,580)\end{array}$ \\
\cline { 2 - 3 } & Menos ruído & $(U=62,500 ;$ & $(U=679,500 ;$ \\
& $p=0,715)$ & $p=0,251)$
\end{tabular}




\begin{tabular}{|c|c|c|c|}
\hline & Melhorar a Climatização & $\begin{array}{l}(U=126,500 \\
p=0,762)\end{array}$ & $(U=9,000 ; p=0,011)$ \\
\hline & Melhorar as instalações & $\begin{array}{l}(U=96,500 \\
p=0,885)\end{array}$ & $\begin{array}{l}(U=45,500 \\
p=0,206)\end{array}$ \\
\hline \multirow[t]{4}{*}{$\begin{array}{l}\text { Gestão dos horários de } \\
\text { trabalho }\end{array}$} & Aumentar as folgas/ férias & $\begin{array}{l}(U=111,000 \\
p=0,593)\end{array}$ & $\begin{array}{l}(U=1162,000 \\
p=0,181)\end{array}$ \\
\hline & Diminuir o tamanho dos turnos & ------ & $\begin{array}{l}(U=114,000 \\
p=0,492)\end{array}$ \\
\hline & Permitir a jornada contínua & $\begin{array}{l}(U=40,500 \\
p=0,791)\end{array}$ & $\begin{array}{l}(U=68,000 \\
p=0,457)\end{array}$ \\
\hline & Aumentar as pausas & -ーーーー- & -ーーー-- \\
\hline \multirow[t]{5}{*}{$\begin{array}{l}\text { Organização da atividade } \\
\text { laboral }\end{array}$} & $\begin{array}{l}\text { Aumentar a rotatividade das } \\
\text { tarefas }\end{array}$ & $\begin{array}{l}(U=40,500 \\
p=0,791)\end{array}$ & $\begin{array}{l}(U=114,000 \\
p=0,154)\end{array}$ \\
\hline & Contratar mais trabalhadores & $\begin{array}{l}(U=40,500 \\
p=0,791)\end{array}$ & $\begin{array}{l}(U=368,500 \\
p=0,840)\end{array}$ \\
\hline & Renovar o material de trabalho & ------ & $\begin{array}{l}(U=266,000 \\
p=0,309)\end{array}$ \\
\hline & $\begin{array}{l}\text { Redução das tarefas/ Alterar as } \\
\text { funções }\end{array}$ & ------ & $\begin{array}{l}(U=112,000 \\
p=0,468)\end{array}$ \\
\hline & Organização do trabalho & $\begin{array}{l}(U=28,000 \\
p=0,852)\end{array}$ & ------ \\
\hline \multirow[t]{2}{*}{$\begin{array}{l}\text { Melhoria das relações } \\
\text { pessoais }\end{array}$} & $\begin{array}{l}\text { Melhorar as relações entre } \\
\text { colegas }\end{array}$ & ------ & $\begin{array}{l}(U=361,500 \\
p=0,760)\end{array}$ \\
\hline & Melhorar as relações com o chefe & $\begin{array}{l}(U=48,500 \\
p=0,613)\end{array}$ & $\begin{array}{l}(U=358,500 \\
p=0,395)\end{array}$ \\
\hline \multirow[t]{2}{*}{$\begin{array}{l}\text { Desenvolvimento } \\
\text { profissional }\end{array}$} & Melhorar o salário & $\begin{array}{l}(U=28,000 \\
p=0,852)\end{array}$ & $\begin{array}{l}(U=112,000 \\
p=0,468)\end{array}$ \\
\hline & Progressão na carreira & ------ & $\begin{array}{l}(U=82,500 \\
p=0,191)\end{array}$ \\
\hline Outros & & $\begin{array}{l}(U=18,500 ; \\
p=0,379)\end{array}$ & ------ \\
\hline
\end{tabular}

A análise dos resultados revela apenas uma associação estatisticamente relevante relativa aos TMV $(U=9,000 ; p=0,011)$, que engloba a "climatização do espaço laboral"; assim, é possível concluir que, neste grupo, os funcionários que sugeriram melhorar a climatização são os que apresentam pior resultado na pontuação do ICT.

\section{DISCUSSÃO}


O estudo de populações de trabalhadores mais velhos serve essencialmente para preparar o futuro no sentido de antecipar as necessidades daqueles que, a curto/ médio prazo, serão a grande força de trabalho nos países Europeus ${ }^{(1)}$.

A opção por estudar um município, onde normalmente, a média de idades dos funcionários é superior (4) possibilitou a obtenção de uma amostra alargada de TMV e compará-la com uma amostra de TMJ, distribuídos por diversos contextos, profissões, categorias profissionais, mas que obedecem à mesma entidade patronal e por isso, partilham as mesmas regras e valores.

A caraterização sociodemográfica da amostra revela similaridades com o que está descrito relativamente à evolução demográfica do trabalho na União Europeia a $28^{(1)}$, que se carateriza por:

a)o predomínio de trabalhadores do sexo masculino no grupo de TMV, que aponta como principais causas a entrada tardia das mulheres no mundo do trabalho, bem como a saída precoce do mundo laboral; observa-se, no entanto, uma progressiva feminização do ambiente laboral, que na amostra está bem representada pelas diferenças proporcionais entre sexos, quando comparado o grupo dos TMV com o dos TMJ;

1. b) a evolução societal em termos educacionais que reflete o aumento gradual da escolaridade verificado nas últimas décadas, tal como foi demonstrado pelas diferenças estatisticamente significativas encontradas entre os dois grupos em estudo, com prejuízo para os TMV, onde ainda predomina a escolaridade básica.

2. c) uma tendência para os TMV desenvolverem atividades predominantemente físicas, apesar da idade e do potencial declínio funcional, facto que ficou estatisticamente demonstrado nas diferenças encontradas entre grupos; é um fenómeno global, uma vez que a escolaridade básica dificulta a evolução para outro tipo de empregos ao longo da vida(1);

3. d) o aumento das responsabilidades familiares que, por vezes, interfere com a capacidade de trabalho e se manifesta com maior intensidade nos TMV, por terem descendentes e/ ou ascendentes ao seu encargo(1), facto que, apesar de não ter sido investigado, é possível suspeitar pelas diferenças encontradas ao nível do estado civil.

\section{ÍNDICE DE CAPACIDADE PARA O TRABALHO}

Para a análise dos valores apurados relativos ao ICT da amostra, efetuou-se uma comparação com os valores de referência existentes para Portugal (7):

- A média relativa ao valor do ICT dos TMV $(37,02 \pm 7,51)$ e dos TMJ $(39,06 \pm 4,59)$ é ligeiramente inferior, em ambos os casos, ao valor de referência aferido para a população portuguesa $(40,52 \pm 5,42)(7)$.

- A percentagem de funcionários classificados com um ICT pobre - TMJ (3\%) e TMV (10,6\%) - é superior aos valores de referência $(2,2 \%)^{(7)}$.

- A percentagem de funcionários classificados com um ICT excelente - TMJ (3\%) e TMV (15,4\%) - é bastante inferior aos 33,2\% da população portuguesa ${ }^{(7)}$.

- Analisando os resultados do ICT segundo os valores de referência por faixa etária (7), sobressai o fraco desempenho dos TMJ $(39,06 \pm 4,59)$, em média, dois pontos abaixo dos valores normais $(41,27 \pm 5,0)$, enquanto os TMV $(37,02 \pm 7,51)$ se situam muito próximos da média considerada normal $(38,0 \pm 6,0)$. 
Apesar dos resultados da amostra serem todos inferiores aos valores de referência para a população portuguesa, eles permanecem dentro do intervalo da curva de distribuição normal, pelo que não são resultados preocupantes. No entanto, a sua análise parece indiciar um sub-rendimento generalizado entre os funcionários, que se mantêm aquém daquilo que poderia ser a sua performance profissional, facto que a comprovar-se poderá ser alvo da intervenção da equipa de saúde ocupacional. De realçar a elevada percentagem de indivíduos com ICT pobre no grupo de TMV, que deverá receber a atenção prioritária por parte desses profissionais.

Para repensar numa estratégia capaz de promover o envelhecimento saudável e produtivo é necessário conhecer os principais fatores facilitadores e também os dificultadores. As diferenças estatisticamente significativas entre os grupos apontam a multimorbilidade e a estimativa do grau de incapacidade daí resultante, como os principais obstáculos para os TMV desenvolverem a sua atividade laboral de uma forma mais plena.

A debilidade do estado de saúde é, portanto, um fator pessoal determinante que afeta a capacidade para trabalhar ${ }^{(7)}$, sendo apontado como causa major para o abandono precoce da vida profissional. Nesse sentido, é fundamental que as empresas desenvolvam políticas de promoção da saúde para todos os trabalhadores, para garantir uma vida profissional mais longa e saudável, podendo a prevenção da doença crónica ser um dos alvos prioritários ${ }^{(1)}$. Simultaneamente, centrando nos TMV, é necessário garantir serviços de acompanhamento que os ajudem a gerir a doença e mantenham a ligação ao trabalho nos períodos de incapacidade temporária, bem como investir em serviços de reabilitação, no sentido de promover a reintegração dos funcionários com deficiência ou reforçar as intervenções precoces para evitar o abandono prematuro do trabalho ${ }^{(1)}$.

Relativamente ao absentismo, apesar de elevado em ambos os grupos, os dados revelaram que, em média, os TMJ faltaram mais no último ano, principalmente no que diz respeito a ausências de curta duração; esse resultado é corroborado pela Agência Europeia para a Segurança e Saúde no Trabalho que revela ser este um contraste aos estereótipos existentes, uma vez que na Europa a 28, o absentismo de curta duração é mais frequente nas camadas mais jovens, o que associado ao fenómeno do turnover (também frequente nestas faixas etárias), torna os TMV mais confiáveis em termos produtivos ${ }^{(9)}$, compensando a sua menor funcionalidade. No entanto não podemos esquecer o fenómeno do presenteísmo, apontado em alguns estudos como mais penalizador para a produção das empresas que o absenteísmo (10) (11), e que, tendo em conta os resultados do ICT e a elevada prevalência de doenças, principalmente nos TMV, poderá ser significativo nestes funcionários.

Os resultados demonstraram ainda que, paradoxalmente, a perceção positiva de valorização profissional se associa a uma maior taxa de absentismo de curta duração, fator que carece de ser explorado melhor para se retirarem conclusões, uma vez que o resultado vai contra a evidência consultada (1).

A incapacidade revelada pelos TMJ para permanecer por mais de dois anos, no atual posto de trabalho, é um fenómeno preocupante, se se considerar que a curto, médio prazo, a capacidade produtiva dos países dependerá muito destes trabalhadores. Assim, começam a existir consensos no sentido de serem tomadas medidas para melhorar as suas condições laborais, por forma a ajudá-los a continuar a trabalhar(1), ou seja, recomendações que apontam para a necessidade de adotar 
estratégias sustentadas de aconselhamento e reorientação profissional na meia-idade (35-45 anos), por forma a estimular a motivação dos trabalhadores, recuperando-os produtivamente dentro das empresas ${ }^{(1)}$.

As diferenças de valores do ICT encontradas entre sexos, nos TMV, estão também estudadas e a evidência aponta para a maior vulnerabilidade das mulheres nesta faixa etária devido a fenómenos como a menopausa, osteoporose e osteoartrite, segregação horizontal (maior desgaste provocado pelo trabalho sedentário ao longo da vida) e vertical (acesso a trabalhos menos remunerados, contratos precários), bem como a coexistência de responsabilidades familiares (cuidadoras familiares) (2) (12). Nos trabalhos em que lidam com o atendimento ao público, como é o caso de algumas das profissões abordadas neste estudo, as mulheres estão também mais sujeitas a situações de assédio, humilhação e violência psicológica por parte dos clientes, expondo-as mais ao stress disfuncional ${ }^{(12)}$.

Por último, importa realçar que os funcionários com atividades intelectuais e científicas, o pessoal administrativo e os trabalhadores não qualificados apresentam, em média, valores de ICT muito inferiores, pelo que deverão ser estudadas medidas para prevenir possíveis complicações nestes setores.

\section{PERCEÇÃO INDIVIDUAL SOBRE A EXIGÊNCIA DA ATIVIDADE}

As diferenças de perceção individual acerca da principal exigência do trabalho não têm influência relevante na capacidade para o trabalho. Como seria de esperar, os funcionários com menos escolaridade e com trabalhos mais físicos, relatam o esforço físico como primordial, enquanto os mais instruídos, que ocupam cargos de gestão e atividades de índole científica (técnicos superiores), a exigência mental.

\section{NÚMERO DE DOENÇAS}

Apesar de estarem ainda no terço inicial das suas carreiras profissionais, o número de doenças referenciado por cerca de $49 \%$ da amostra de funcionários com idade inferior a 35 anos, é já elevado $(1,58 \pm 1,95)$ e é ainda superior nos TMV. Este resultado vai de encontro aos valores apresentados pelo Eurostat que colocam Portugal na cauda da Europa em termos de esperança de vida sem incapacidade física após os 65 anos (13) (14), com particular incidência sobre o sexo feminino que aparece em primeiro lugar em termos de maior número médio de anos de vida não saudável após os 65 anos (16,3 anos). Assim, os resultados permitem concluir que é urgente repensar em medidas de promoção da saúde numa fase precoce da vida laboral para assegurar, no futuro, a existência de TMV saudáveis e produtivos.

\section{PERCEÇÃO SENSORIAL (VISÃO E AUDIÇÃO)}

Ao nível da perceção sensorial, apesar da grande maioria dos funcionários referir que vê e ouve bem, é de realçar a existência de problemas de visão em 21,2\% e de audição em 9,1\% dos TMJ, fatores que carecem de ser trabalhados para assegurar, no presente e principalmente, no futuro, a capacidade laboral destes indivíduos. Analisando as caraterísticas da amostra de TMJ, infere-se que a existência de fenómenos, como a síndrome de visão de computador, têm tendência para ser mais prevalentes devido à maior predisposição para utilizar dispositivos eletrónicos, aumentando a suscetibilidade futura de terem problemas visuais que afetem a capacidade laboral (15). 
Independentemente das causas, fica comprovado que nesta amostra a perceção de perda da capacidade visual e auditiva influencia negativamente a capacidade para o trabalho, principalmente nos TMV, fator que deverá ser tido em conta pela ESO por forma a rastrear e atuar devidamente sobre os indivíduos afetados, bastando por vezes, a introdução de simples ajudas ou ajustamentos no trabalho ${ }^{(9)}$.

\section{IDADE IDEALIZADA PARA A REFORMA}

Os resultados evidenciados no estudo comprovam que, apesar das políticas europeias serem consonantes no que diz respeito ao aumento para a idade da reforma (1), algo também sentido em Portugal, os trabalhadores continuam a pensar no sentido inverso ( $28 \%$ dos trabalhadores europeus considera que não irá conseguir trabalhar até os 60 anos, principalmente os mais novos $\left.{ }^{(1)}\right)$ esperando conseguir uma reforma antecipada. Esse fator torna-se ainda mais relevante pelo facto de serem os TMJ a desejar reformar-se mais cedo, pelo que se considera que este resultado pode ser um forte indicador da necessidade de mudança.

Relativamente aos TMV a evidência de que existe correlação positiva entre o ICT e a idade idealizada para a reforma, reforça ainda mais a necessidade de serem criadas as condições para a otimização das capacidades laborais dos funcionários, assegurando assim o seu trabalho por mais anos, tal como refere a bibliografia consultada ${ }^{(1)}$.

Contudo, não pode ser descurado o facto de que, pela sua idade avançada, alguns dos TMV refiram, obrigatoriamente, uma idade superior à dos restantes para a idade da reforma.

\section{POSSIBILIDADE DE REFORMA PROGRESSIVA}

Uma das medidas avançadas para o desenvolvimento de ambientes de trabalho sustentáveis, capazes de reter os TMV produtivos, é a existência de planos de reforma progressiva, com redução de horas de trabalho e a adoção de regimes flexíveis e adequados, especialmente para quem tem problemas de saúde ou responsabilidades enquanto cuidadores familiares ${ }^{(9)}$.

Apesar de cerca de 40\% dos TMV concordar com a medida, ela não é aceite pelos TMJ. Infere-se que esta ausência de sensibilidade por parte dos funcionários mais novos possa ser atribuída a fatores como a ausência de conhecimento, o que exigiria ações para aumentar a literacia sobre este assunto; o grande espaço temporal que os separa da idade da reforma, que não permite que visualizem a medida como benéfica para eles; ou o medo de sobrecarga laboral, dada a dificuldade atual de admitir novos funcionários públicos para assegurar os períodos de ausência dos TMV. Nesse sentido, a implementação deste tipo de políticas exigiria outros recursos que no momento atual, ainda não se vislumbram.

Relativamente às diferenças encontradas nos TMV, justifica-se que essa possibilidade seja rejeitada pelos funcionários que têm profissões hierarquicamente superiores e/ou intelectualmente complexas, como é o caso dos representantes de órgãos executivos e dos especialistas em atividades científicas pois, segundo a evidência, mantêm os objetivos e expectativas laborais e consideram o seu trabalho compensatório, tendo tendência para se manterem a trabalhar após a idade oficial da reforma (1). No entanto, considerando que ocupam posições de gestão de pessoal, também não será de descurar a possibilidade de temerem tal medida, face à escassez de recursos humanos. 


\section{VALORIZAÇÃO POR PARTE DO EMPREGADOR}

Os resultados do estudo apontam para a perceção dos TMV de serem menos valorizados pela entidade empregadora, do que os TMJ. Segundo a bibliografia consultada, sentimentos de discriminação podem acontecer, essencialmente nas idades limítrofes (mais novos e mais velhos) e a consciencialização para estas situações poderá fazer mudar a atitude no sentido da valorização das capacidades totais dos TMV, por forma a manter a sua motivação e preservar a sua capacidade produtiva (1) (9). Tal como já foi afirmado, TMV motivados constituem um trunfo para as organizações, pois são mais experientes, empenhados e fiáveis, têm mais conhecimentos e competências, sendo inferiores o turnover e o absentismo a curto prazo ${ }^{(9)}$.

\section{VALORIZAÇÃO POR PARTE DAS CHEFIAS E AMBIENTE LABORAL}

Os funcionários, no global, não se sentem discriminados pelos seus superiores hierárquicos e, na sua maioria, consideram o ambiente de trabalho facilitador para a prática laboral, factos que poderão ser operacionalizados no futuro, como fatores de proteção para a preservação da capacidade de trabalho ${ }^{(1)}$.

Realça-se, no entanto, que apenas os TMV referiram a existência de ambientes prejudiciais (maus e muito maus), ao que se associa um decréscimo na capacidade laboral, fatores que devem ser explorados pela ESO para procura de medidas específicas de apoio aos trabalhadores mais vulneráveis ${ }^{(9)}$.

\section{FATORES A MUDAR NO LOCAL DE TRABALHO}

O número de sugestões de melhoria relativamente ao contexto laboral foi muito reduzido o que, juntamente com o que foi referido na alínea anterior, parece querer indicar que existem boas condições para a prática laboral, não sendo este um fator preponderante para justificar o decréscimo de motivação por parte dos TMV.

Relativamente ao espaço físico, os TMJ são os mais inconformados, sugerindo melhorias estruturais para diminuir os fatores que perturbam a sua capacidade de trabalho, facto que pode ser aproveitado para, desde já, começar a desenvolver esforços para proporcionar boas condições de trabalho, promotoras da saúde física e mental ${ }^{(9)}$, tendo em conta as expectativas dos trabalhadores; são, por isso, oportunidades para o desenvolvimento de uma cultura institucional rumo a um trabalho sustentável ao longo de toda a vida laboral (1). Importa aqui realçar a "redução do ruído", que emerge como a segunda sugestão mais vezes referenciada por todos os funcionários e que, pelos efeitos patológicos que exerce sobre os trabalhadores(16), deve fazer parte de qualquer programa de melhoria das condições laborais, bem como ser alvo de avaliação contínua por parte da ESO.

Apesar da hipótese de reforma progressiva não ser totalmente bem aceite, há uma parte significativa dos funcionários que refere o aumento do número de "férias e/ou folgas", como promotor da capacidade de trabalho, ou seja, depreende-se que a redução do horário de trabalho é observada como uma medida positiva, embora não seja vista pelos funcionários como uma opção que deve ser proporcionada somente aos TMV. Infere-se, por isso, que de futuro, poderá ser importante proporcionar aos funcionários formação acerca das necessidades específicas associadas ao envelhecimento laboral, para que todos possam ser envolvidos, contribuindo ativamente para o desenvolvimento de políticas institucionais saudáveis. 
Ao nível das relações interpessoais, apesar de, nos pontos anteriores, a relação com os superiores hierárquicos e colegas de trabalho aparentar ser mais saudável do que com a entidade patronal, ao nível das sugestões emerge a relação com as chefias como um ponto de possível e desejável melhoria. A diferença talvez se explique pela proximidade existente, uma vez que com os superiores hierárquicos há um contacto diário que interfere diretamente com o trabalho, algo que não acontece com os responsáveis pela entidade patronal. Independente disso, o apoio dos superiores hierárquicos é considerado fundamental para a saúde física e mental dos TMV, bem como para preservar a sua capacidade de trabalho (1) (9), devendo, por isso, ser alvo de monitorização e intervenção por parte da Equipa de Saúde Ocupacional.

\section{CONCLUSÕES}

O estudo abordou o fenómeno do envelhecimento laboral num município de média dimensão, no sul do país (Albufeira).

A sua concretização permitiu traçar o perfil dos TMV, verificando-se que são predominantemente casados, possuindo maioritariamente apenas um dos ciclos de ensino básico e, ocupando, por isso, empregos menos diferenciados.

As diferenças são também significativas quando se compara a avaliação que fazem sobre a capacidade laboral destacando-se, em média, nos TMV, uma maior morbilidade e sensação de incapacidade face à doença, bem como uma perceção mais negativa associada à capacidade intrínseca atual, à capacidade face às exigências da tarefa e relativa aos recursos psicológicos disponíveis, o que os coloca numa situação de maior vulnerabilidade face aos TMJ. Acrescenta-se ainda uma taxa superior de absentismo de longa duração, bem como as limitações ao nível da perceção sensorial (visual e auditiva) que afetam particularmente a sua capacidade laboral.

No que diz respeito ao ambiente e relações interpessoais, os TMV acreditam que a entidade patronal valoriza menos o seu trabalho em relação aos restantes e são os únicos que referem a existência de ambientes de trabalho maus ou muito maus. Não apresentam, contudo, muitas sugestões de melhoria.

Relativamente à idade que idealizam para a reforma, comprova-se uma relação direta com capacidade para o trabalho (avaliada com o ICT) embora pareçam pouco informados acerca das medidas que, potencialmente, poderiam ser facilitadoras e promotoras da sua saúde física, metal e capacidade laboral- tais como um plano de reforma progressiva. Sugerem, no entanto, o aumento do número de férias/ folga como facilitador.

Sintetizando, com este estudo foi possível comprovar a maior vulnerabilidade dos TMV, sendo por isso fundamental pensar em medidas estruturais e processuais de suporte para que este grupo etário, possa prosseguir a sua carreira profissional de forma saudável e motivada, e assegurar a sua permanência no mundo do trabalho, uma vez que caminhamos rapidamente para uma era onde a sua participação será fundamental.

O estudo encontrou também algumas questões que ficaram por responder por não terem sido equacionadas mas que carecem de resposta. Há, por isso, necessidade de se realizarem mais estudos para retratar a realidade dos TMV em Portugal, por forma a contribuir com conhecimento capaz de 
influenciar as políticas de saúde e laborais, rumo a um trabalho seguro e de qualidade, para todas as idades.

\section{REFERÊNCIAS BIBLIOGRÁFICAS}

1- EU-OSHA, Cedefop, Eurofound e EIGE. Towards age-friendly work in Europe: a life-course perspective on work and ageing from EU Agencies. Publications Office of the European Union. 2017: 187. DOI: $10.2802 / 130548$.

2- Santos M e Almeida A. Saúde ocupacional aplicada a trabalhadores menos jovens. Revista Portuguesa de Saúde Ocupacional. 2017; Vol. 3: S39-S52. DOI: 10.31252/RPSO.15.03.2017.

3- Eurostat, Instituto Nacional de Estatística e PORDATA. População activa: por grupo etário (\%). PORDATA. [Online], 2018. https://www.pordata.pt/Europa/ Popula\%c3\%a7\%c3\%a3o+activa+por+grupo+et\%c3\%a1 rio +(percentagem)-1757-214693.

4- Ybema J e Giesen F. Older workers. OSHWIKI Networking Knowledge. [Online], 2017. https://oshwiki. eu/wiki/Older_workers\#Sectors.

5- Pinho R. Fatores de risco/riscos psicossociais no local de trabalho. Direção-Geral da Saúde. [Online], $2015 . \quad$ file:///C:/Users/aalmeida/AppData/Local/Packages/Microsoft. MicrosoftEdge_8wekyb3d8bbwe/TempState/Downloads/i024104\%20(1).pdf.

6- Costa A. Riscos Psicossociais e Capacidade no Trabalho na população de Outil (Cantanhede). Faculdade de Medicina da Universidade de Coimbra - dissertação de mestrado em saúde ocupacional. [Online], 2015. http://hdl.handle.net/10316/29794.

7- Silva C. Índice de Capacidade para o Trabalho. Portugal e países africanos de língua oficial portuguesa. Análise Exacta - Consultadoria, Formação e Edição de livros. 2011.

8- Martinez M, Latorre M e Fischer F. Capacidade para o trabalho: revisão de literatura. Ciência \& Saúde Coletiva. 2010; Vol. 15 (Suplemento 1): 1553-1561.

9- Crawford J, Davis A, Cowie H e Dixon K. The ageing workforce: Implications for occupational safety and health A research review. European Agency for Safety and Health at Work. [Online], 2016. file:///C:/Users/aalmeida/AppData/Local/Packages/

Microsoft.MicrosoftEdge8wekyb3d8bbwe/TempState/Downloads/the-ageing-workforce-implicationsfor-occupational-safety-and-health-a-research-review-executive-summary \%20(1).pdf

10- Allen D, Hines E, Pazdernik V, Konecny L e Breitenbach E. Four-year review of presenteeism data among employees of a large United States health care system: a retrospective prevalence study. Human Resourses for Health. 2018; Vol. 16 (1): 59.

11- Schultz A, Chen C e Edington D. The cost and impact of health conditions on presenteeism to employers: a review of the literature. Pharmacoeconomics. 2009; Vol. 27 (5): 365-378.

12- Crawford J, Davis A, Cowie H e Dixon K. Women and the ageing workforce Implications for Occupational Safety and Health. A research review. European Agency for Safety and Health at Work. [Online], 2016. https://osha.europa.eu/en/tools-and-publications/publications/safer-and-healthier- 
work-any-age-women-and-ageing-workforce-1/view

13- Fundação Francisco Manuel dos Santos. Esperança de vida aos 65 anos da população do sexo feminino: total e por anos de vida saudável e não saudável - Europa. PORDATA. [Online], 2016. https://www.pordata.pt/Europa/Esperança+de+vida+aos+65+anos+da+ população+do+sexo+feminino+total+e+por+anos+de+vida+saudável+e+não+saudável-2808.

14- Fundação Francisco Manuel dos Santos. Anos de vida saudável aos 65 anos: por sexo - Europa. PORDATA. [Online], 2016. https://www.pordata.pt/Europa/Anos+de+vida+ saudável+aos+65+anos+por +sexo-1590.

15- Rosenfield M. Computer vision syndrome: a review of ocular causes and potential treatments. Ophthalmic \& Physiological Optics. 2011; Vol. 31: 502-515.

16- Santos M e Almeida A. Ruído e saúde ocupacional: Consequências para além da hipoacusia. 2016; Vol. 1: S128-S130. DOI:10.31252/RPSO.24.03.2016

(1)Armando Almeida

Doutorado em Enfermagem; Mestre em Enfermagem Avançada; Especialista em Enfermagem Comunitária; Pós-graduado em Supervisão Clínica e em Sistemas de Informação em Enfermagem; Docente na Universidade Católica Portuguesa, Instituto da Ciências da Saúde Escola de Enfermagem (Porto); Diretor Adjunto da Revista Portuguesa de Saúde Ocupacional on line. Rua Agostinho Fernando Oliveira Guedes, 42, 4420-009 Gondomar E-mail: aalmeida@porto.ucp.pt.

\section{(2)Mónica Santos}

Licenciada em Medicina; Especialista em Medicina Geral e Familiar; Mestre em Ciências do Desporto; Especialista em Medicina do Trabalho e Doutoranda em Segurança e Saúde Ocupacionais, na Faculdade de Engenharia da Universidade do Porto. Presentemente a exercer nas empresas Medicisforma, Servinecra e Securilabor; Diretora Clínica das empresas Quercia e Gliese; Diretora da Revista Portuguesa de Saúde Ocupacional on line. 4420-009 Gondomar. Email: s_monica_santos@hotmail.com.

\section{(3)Celso Mendes}

Mestre em Segurança e Higiene do Trabalho, Pós-graduado em Sistemas de Gestão de Ambiente, Qualidade e Segurança, Pós-graduado em Saúde e Segurança do Trabalho. É licenciado em Ciências Sociais e Bacharel em Engenharia Agrícola. Exerceu funções na Administração Central no âmbito dos Sistemas de Qualidade, e da gestão de recursos humanos. Desenvolve atividade como Técnico Superior de Segurança no Trabalho, no Município de Albufeira, sendo técnico de segurança certificado desde 2002. Desenvolve ainda atividade como Formador em diversas ações de formação nesta área de atividade. 8201-863 Albufeira. E-mail: celso.mendes@cm-albufeira.pt

(4)Marta Catuna Machadinho 
Licenciada em Psicologia Cínica, têm competências e formação em Hipnoterapia Clínica, Arteterapia e Psicologia Transpessoal, estando atualmente a trabalhar em Psicologia do Trabalho, no Município de Albufeira. Para além desta atividade profissional, é ainda colaboradora e hipnoterapeuta qualificada pelo Grupo de Hipnose Psicológica do Colégio Oficial de Psicólogos da Comunidade Valenciana (Valência, Espanha). 8201-863 Albufeira. E-mail: marta.machadinho@cm-albufeira.pt 